\title{
Sistema sexual e biologia floral de Pouteria ramiflora e P. torta (Sapotaceae) ${ }^{1}$
}

\author{
LUCILENE UMBELINO GAMA ${ }^{2,3}$, ANA ANGÉLICA ALMEIDA BARBOSA² e \\ PAULO EUGÊNIO ALVES MACEDO DE OLIVEIRA ${ }^{2}$
}

(recebido: 21 de outubro de 2010; aceito: 07 de julho de 2011)

\begin{abstract}
Sexual system and floral biology of Pouteria ramiflora and P. torta (Sapotaceae)). Pouteria ramiflora and P. torta are tree species sympatric in the Cerrado and were studied in the Natural Reserve of Clube Caça e Pesca Itororó (Uberlândia-MG) in order to compare various aspects of their reproductive biology. The phenophases were evaluated weekly and their intensity was quantified. The floral biology, breeding system, sexual system and floral visitors were studied in the field and/or laboratory. In both species, leaf fall occurred in the end of the dry season, leaf flushing between the dry and the rainy season, flowering in the dry season and fruit maturation during the rainy season. They have tubular small greenish flowers, with small amounts of nectar and high pollen viability. They are self-sterile, non-agamospermic and had low fruiting success from natural pollination. $P$. torta is a hermaphrodite species, with protogynous and hercogamous flowers, while $P$. ramiflora is morphologically gynomonoecious but functionally unisexual. The apparently low pollen flow and the abortion of young fruits resulted in low fruit set from natural pollinations. Both species are visited by several small insects, including butterflies, moths, flies and bees.
\end{abstract}

Key words - Cerrado, dichogamy, monoecy, pollination, self-incompatibility

RESUMO - (Sistema sexual e biologia floral de Pouteria ramiflora e P. torta (Sapotaceae)). Pouteria ramiflora e P. torta são espécies arbóreas, simpátricas no Bioma Cerrado, e foram estudadas da Reserva Ecológica do Clube Caça e Pesca Itororó, Uberlândia-MG com o objetivo de comparar os vários aspectos de sua biologia reprodutiva. As fenofases foram avaliadas semanalmente e quantificadas quanto à intensidade. Os dados de biologia floral, sistema reprodutivo, sistema sexual e visitantes florais foram obtidos no campo e/ou no laboratório. As espécies apresentaram caducifolia no final da seca, brotação na transição da seca para o período chuvoso, floração na seca e maturação dos frutos na época chuvosa. Ambas possuem flores tubulares, pequenas e esverdeadas, nectaríferas e com viabilidade polínica alta. São autoestéreis e não agamospérmicas e apresentaram baixo sucesso de frutificação na polinização aberta. $P$. torta é hermafrodita, com flores protogínicas e hercogâmicas, enquanto $P$. ramiflora é morfologicamente ginomonóica e funcionalmente monóica. O fluxo de pólen aparentemente baixo entre as plantas e o aborto de frutos jovens resultaram em um pequeno sucesso de frutificação proveniente das polinizações naturais. Ambas as espécies são visitadas por diversos pequenos insetos, como borboletas, mariposas, dípteros e abelhas.

Palavras-chave - autoincompatibilidade, Cerrado, dicogamia, monoicia, polinização

\section{Introdução}

Entre as angiospermas, existe uma variedade de sistemas sexuais, que envolvem mecanismos temporais e/ou morfológicos de separação sexual como a protandria, a protoginia, a heterostilia, a monoicia, a dioicia e as suas variações. Alguns autores propõem que a diversidade de sistemas sexuais é resultado de uma pressão seletiva para o aumento da fertilização cruzada e da recombinação genética nas plantas (Lewis 1942, Darlington 1958, Grant 1958, Stebbins 1958, Mather 1973). No entanto, outras

1. Parte da monografia da primeira autora, Curso de Ciências Biológicas, Universidade Federal de Uberlândia, Uberlândia, MG, Brasil.

2. Universidade Federal de Uberlândia, Campus Umuarama, Instituto de Biologia, Bloco 2D, Caixa Postal 593, 38400-902 Uberlândia, MG.

3. Autor para correspondência: lucilenegama@gmail.com explicações são sugeridas para a evolução dos sistemas sexuais, como o aperfeiçoamento da alocação de recursos para a função feminina e masculina das flores (Charnov et al. 1976, Maynard-Smith 1978, Bawa 1980, Willson 1983), a seleção sexual (Charnov 1979, Willson 1979, Bawa 1980), o sistema de polinização (Bawa 1980) e o comportamento dos polinizadores (Bawa \& Beach 1981).

Apesar dos diferentes sistemas sexuais existentes, cerca de $80 \%$ das angiospermas é hermafrodita (Richards 1997). Nas espécies com flores hermafroditas, é comum a existência de adaptações para evitar a autopolinização e/ou a autofertilização como, por exemplo, a hercogamia, a dicogamia e a presença de mecanismos genéticos de autoincompatibilidade. A autoincompatibilidade é o mecanismo mais comum pelo qual as plantas evitam a autofertilização, atuando como uma barreira fisiológica que dificulta ou impossibilita que uma flor seja 
autofertilizada mesmo que tenha sido abundantemente polinizada com o seu próprio pólen (Richards 1997). Porém, devido à possibilidade da autopolinização ocorrer até mesmo nas espécies autoincompatíveis, os sistemas sexuais distintos do hermafroditismo podem separar a função feminina e masculina das flores, evitando os conflitos de gênero e os custos fisiológicos da autoincompatibilidade (Lloyd \& Webb 1986, Harder et al. 2000). Estes sistemas sexuais podem envolver separação temporal, espacial ou ambas as estratégias (Lloyd \& Webb 1986, Bertin 1993).

A família Sapotaceae compreende 11 gêneros e cerca de 450 espécies neotropicais com representantes desde o sul dos Estados Unidos até Paraguai, Uruguai e Chile (Pennington 1990, Ribeiro 1999). São elementos importantes em florestas úmidas mas ocorrem em savanas e em zonas semiáridas (Pennington 1990). No bioma Cerrado, ocorrem pelo menos sete gêneros e cerca de 20 espécies, sendo sete do gênero Pouteria (Mendonça et al. 1998).

As espécies da família Sapotaceae são de porte arbóreo ou arbustivo, e possuem látex, geralmente branco, em todas as partes da planta (Ribeiro 1999). As flores são pequenas, de cor pouco vistosa (creme, amarela ou esverdeada) (Pennington 1990). Na família, ocorrem tanto espécies hermafroditas (Manilkara, Pradosia e maioria das espécies de Sideroxylon) como unissexuais (especialmente Pouteria e Chrysophyllum), com plantas freqüentemente dióicas e ocasionalmente monóicas (Pennington 1990). A protoginia foi confirmada em Argania spinosa (L.) Skeels) (Nerd et al. 1998), Madhuca indica J. F. Gmel. (Kuruvilla \& Shah 1988), Manilkara subsericea (Mart.) Dubard e Sideroxylon obtusifolium (Roem. \& Schult.) T.D. Penn., e protandria para Chrysophyllum auratum Miq. (Corrales et al. 1986) e C. oliviforme L. (Tomlinson 1974).

Quanto à polinização, há desde espécies visitadas por pequenos insetos, como abelhas e moscas, até espécies possivelmente polinizadas por morcegos e marsupiais (Pennington 1990). Há registro de que Manilkara subsericea e Sideroxylon obtusifolium são visitadas por insetos das ordens Hymenoptera, Lepidoptera, Coleoptera, Diptera e Thysanoptera (Gomes et al. 2010), Chrysophyllum auratum é visitada por trips e moscas (Corrales et al. 1986) e Pouteria venosa (Martius) Baehni é polinizada por dípteros e coleópteros noturnos (Gomes \& Pinheiro 2007).

Embora existam estudos envolvendo sistema sexual e biologia floral de muitas espécies de Cerrado (Oliveira \& Gibbs 2000), não existem estudos mais aprofundados com espécies de Sapotaceae neste bioma. A polinização por pequenos insetos e a dioicia foi relatada para Pouteria ramiflora (Mart.) Radlk. (Oliveira 1996), mas pouco se sabe sobre o sistema sexual e a polinização de $P$. torta (Mart.) Radlk., espécie simpátrica e igualmente comum em ambientes abertos da região. Neste sentido, o presente trabalho objetivou o estudo da fenologia, sistema sexual e biologia floral de Pouteria ramiflora e $P$. torta, de modo a ampliar as informações sobre a biologia reprodutiva das Sapotaceae na região.

\section{Material e métodos}

Local de estudo - O estudo foi realizado em uma área de cerrado sentido restrito da Reserva Ecológica do Clube Caça e Pesca Itororó de Uberlândia (CCPIU, 18 $8^{\circ} 57^{\prime} \mathrm{S}$ e $48^{\circ} 12^{\prime} \mathrm{W}$ ), situada a oeste do município de Uberlândia, $\mathrm{MG}$, a $8 \mathrm{~km}$ do perímetro urbano. Esta reserva possui uma área de 127 ha, onde ocorre uma extensa vereda com pequenas manchas de mata de brejo, e as fisionomias de campo sujo e cerrado (sentido restrito), sendo esta última, a cobertura vegetal dominante. De acordo com a escala de Köppen, o clima da região de Uberlândia é do tipo Aw megatérmico e caracterizase por duas estações bem definidas, sendo um verão quente $\mathrm{e}$ úmido com temperaturas acima de $35^{\circ} \mathrm{C}$ e um inverno frio e seco com possibilidade de geadas (Rosa et al. 1991).

Espécies estudadas - Pouteria ramiflora (Sapotaceae) é uma árvore que mede cerca de $10 \mathrm{~m}$ de altura e que está distribuída no centro e no sul do Brasil, estendendo-se ao norte para a Amazônia e a oeste para a Bolívia, com registro no Paraguai (Pennington 1990). No Cerrado, ocorre nas fisionomias de cerradão, cerrado sentido restrito, cerrado ralo, borda de vereda e mata mesofítica (Almeida et al. 1998). Por apresentar crescimento moderado e adaptação a lugares abertos, é indicada para plantio em áreas de preservação permanente (Lorenzi 1992).

Pouteria torta (Sapotaceae) tem porte arbóreo, podendo medir de 8 a $14 \mathrm{~m}$ de altura (Lorenzi 1992) e sua distribuição ocorre desde o México, passando pela América Central até o Paraguai, na América do Sul (Pennington 1990). No Brasil, pode ser encontrada em florestas semidecíduas, florestas pluviais e cerrado, e distribuída desde a região amazônica até Goiás, Rio de Janeiro, Minas Gerais, São Paulo, Bahia e Paraná. É uma espécie considerada importante em plantios para recomposição de áreas degradadas e de preservação permanente, pois apresenta características ornamentais úteis para arborização e produz muitos frutos anualmente, que servem de alimento para as espécies da fauna (Lorenzi 1992).

Fenologia - Em Pouteria ramiflora, o estudo fenológico foi realizado no período de junho de 2005 a maio de 2007 ( $n=22$ indivíduos nos primeiros 12 meses e $n=32$ nos meses posteriores) e em $P$. torta, de junho de 2006 a maio de 2007 ( $n=5$ indivíduos). A densidade de P. torta na área 
é bem menor do que a de P. ramiflora (Faleiro 2007), além de poucos indivíduos terem florescido durante o estudo, o que explica o pequeno número de plantas utilizadas. Por outro lado, no segundo ano de estudo, novos indivíduos de $P$. ramiflora foram incluídos devido à necessidade de observar a expressão sexual possivelmente diferente entre os indivíduos dessa espécie. As observações fenológicas foram feitas semanalmente, avaliando-se as seguintes fenofases: queda foliar (caducifolia), brotação, floração e frutificação. Considerou-se como caducifolia a queda das folhas após a mudança da coloração verde para amarelada com aspecto seco; como brotação, o aparecimento de folhas novas, pequenas e de cor avermelhada; como floração, o início do aparecimento dos primórdios de botões florais até as últimas flores abertas; e como frutificação, o início da formação dos frutos até a maturação destes. A intensidade mensal de cada fenofase foi calculada em porcentagem conforme Bencke \& Morellato (2002).

Biologia floral - Todas as análises da biologia floral foram realizadas em pelo menos cinco indivíduos de cada uma das espécies. A descrição da morfologia floral em P. ramiflora e em P. torta foi feita a partir da análise das flores no campo e no laboratório (material fresco ou conservado em etanol $70 \%)$.

A morfometria floral e a quantidade de óvulos foram obtidas em 70 flores de P. ramiflora e 35 flores de P. torta. Para a morfometria, foi utilizado paquímetro analógico com $0,01 \mathrm{~mm}$ de precisão. As diferenças entre tipos florais e espécies foram testadas par a par utilizando teste $t$ (Sokal \& Rohlf 1981).

O horário de abertura das flores foi definido a partir da marcação de botões em pré-antese ( $n=40$ em Pouteria ramiflora; $n=30 \mathrm{em}$ P. torta). Como pré-antese, considerouse a fase em que as pétalas estão totalmente expostas, mas permanecem fechadas. Após a abertura, a longevidade dessas flores foi obtida acompanhando-as até o último dia em que permaneceram abertas.

A receptividade estigmática foi avaliada no campo, com uso de lupa manual com aumento de $10 \mathrm{X}$, e confirmada no laboratório sob estereomicroscópio de luz, aplicando-se algumas gotas de água oxigenada 3\% (dez volumes) nos estigmas (Kearns \& Inouye 1993). A reação à água oxigenada, a partir da formação de bolhas, foi considerada indicativo de receptividade. Nas duas espécies, foram analisados botões fechados $(n=10)$, botões em pré-antese $(n=10)$ e flores abertas $(n=10)$.

Em $P$. ramiflora e $P$. torta, a fase da liberação de pólen foi verificada no campo, em botões em pré-antese $(n=5) \mathrm{e}$ em flores abertas $(n=5)$, ambos previamente ensacados com sacos de organza de náilon. No laboratório, foram analisados botões fechados $(n=5)$ sob estereomicroscópio para conferir a existência de pólen liberado nesta fase. A proporção de grãos de pólen viáveis foi obtida em botões $(n=15)$, utilizando-se microscopia óptica e contador manual. Para cada botão, as anteras foram retiradas, maceradas e coradas com carmin acético (1,2\%) em uma lâmina semipermanente, onde foram analisados os 300 primeiros grãos de pólen presentes no campo de visão, com objetiva de aumento 40 X (Kearns \& Inouye 1993).

O volume de néctar foi medido em flores recém-abertas ( $n=9$ para cada espécie) previamente ensacadas, utilizando microcapilares de vidro de $1 \mu \mathrm{lem} P$. ramiflora e de $10 \mu \mathrm{l}$ em P. torta. Cada flor foi avaliada uma única vez em função de sofrerem danos durante a medição. A concentração do néctar foi medida usando-se refratômetro manual ajustado para medidas de sacarose (Dafni et al. 2005).

A existência de odor nas flores foi avaliada colocando-se vários ramos com flores recém abertas em frascos de vidro, que foram tampados por 20 minutos e posteriormente abertos para verificar a presença e o tipo de odor.

Sistema reprodutivo - O sistema reprodutivo de Pouteria ramiflora e de $P$. torta foi avaliado realizando-se polinizações controladas em cinco indivíduos de cada espécie, durante a floração de 2005 e 2006. Cada experimento foi realizado em um mínimo de 20 flores de cada espécie, que foram mantidas ensacadas com sacos de organza de náilon da fase de botão até fruto, exceto no caso das polinizações naturais (controle). Neste caso, os botões foram apenas marcados com cola e/ ou fio de plástico coloridos nos ramos das plantas, contados e mantidos em aberto. A autopolinização manual foi feita depositando-se o pólen sobre o próprio estigma em flores recém-abertas. A autopolinização espontânea foi avaliada deixando os botões ensacados, sem realização de polinizações experimentais. A apomixia autônoma (agamospermia diplospórica) foi testada removendo-se todas as anteras dos botões, que posteriormente foram mantidos ensacados. A polinização cruzada foi realizada em flores recém-abertas, depositando-se sobre o estigma destas, pólen de flores de outro indivíduo localizado a pelo menos $30 \mathrm{~m}$ de distância. $\mathrm{O}$ desenvolvimento dos frutos até a maturação foi considerado como sucesso de frutificação para todos os tratamentos.

Sistema sexual - Em 2005, o sistema sexual de P. ramiflora foi investigado, no campo, pela observação das flores na copa das plantas ( $n=26$ plantas), quanto à presença de pistilo $\mathrm{e}$ de anteras com pólen. No laboratório, amostras de flores coletadas em um mínimo de cinco inflorescências de 22 indivíduos foram analisadas sob estereomicroscópio quanto à presença de anteras férteis e de óvulos bem formados no ovário. Em 2006, uma média de 45 flores foi coletada de sete indivíduos e analisada no laboratório apenas quanto à presença de anteras com pólen. A funcionalidade das estruturas reprodutivas das flores foi conferida a partir das autopolinizações e das polinizações cruzadas manuais realizadas nos testes reprodutivos descritos anteriormente.

O sistema sexual de $P$. torta foi averiguado pela análise morfológica das flores de diferentes indivíduos $(n=5)$ da área de estudo e pela realização de polinizações cruzadas nestes indivíduos, buscando-se verificar a existência de separação espacial e/ou temporal na função sexual das flores. As polinizações cruzadas foram realizadas em flores com 
as pétalas fechadas, mas com o estigma já exposto $(n=5)$ e em flores abertas com tempo de abertura indefinido $(n=12)$, ambos previamente ensacados.

Sistema de polinização - Os visitantes florais das espécies foram observados em diferentes indivíduos $(n=5$ para cada espécie) na área de estudo e identificados diretamente no campo até o nível de ordem. Em Pouteria ramiflora, as observações foram realizadas em 2005 e 2006, totalizando 15 horas (10 horas no primeiro ano e cinco horas no segundo); e em P. torta em 2006, totalizando cinco horas. O período diário das observações variou de 30 minutos até uma hora e meia, em horários aleatórios, entre $8 \mathrm{~h} 00$ e $17 \mathrm{~h} 30$, sendo que em $P$. ramiflora também foi feita uma observação noturna em 2005 , entre $18 \mathrm{~h} 00$ e $21 \mathrm{~h} 00$. Estas observações foram limitadas pela sobreposição de várias atividades da pesquisa e pela logística de acesso à área.

Para P. ramiflora, os insetos foram capturados com rede entomológica e sacrificados em câmara mortífera contendo algodão embebido em acetato de etila. Em função das limitações no período de observação em $P$. torta, apenas as abelhas foram coletadas e identificadas. Os insetos coletados nas flores foram analisados sob estereomicroscópio quanto à presença de grãos de pólen no corpo e montados a seco para identificação e inclusão na Coleção Entomológica do Instituto de Biologia da Universidade Federal de Uberlândia. No caso de $P$. ramiflora, foram preparadas lâminas semi-permanentes com o pólen das flores, usando-as para comparar com o pólen aderido ao corpo dos insetos.

\section{Resultados e discussão}

Fenologia - Nos dois anos de estudo, a caducifolia em $P$. ramiflora ocorreu de agosto a setembro, no final da estação seca e no período da sua floração (figura 1). Porém, em 2005, os indivíduos que produziram uma maior quantidade de frutos perderam todas as folhas durante a maturação destes e só iniciaram a brotação em 2006, juntamente com os demais indivíduos da população (figura 1). A queda foliar em $P$. torta ocorreu durante todo o mês setembro, também no final da estação seca e durante a sua floração (figura 1). A caducifolia no final da estação seca, como verificado nas espécies estudadas, é comum em espécies arbóreas de cerrado (Franco et

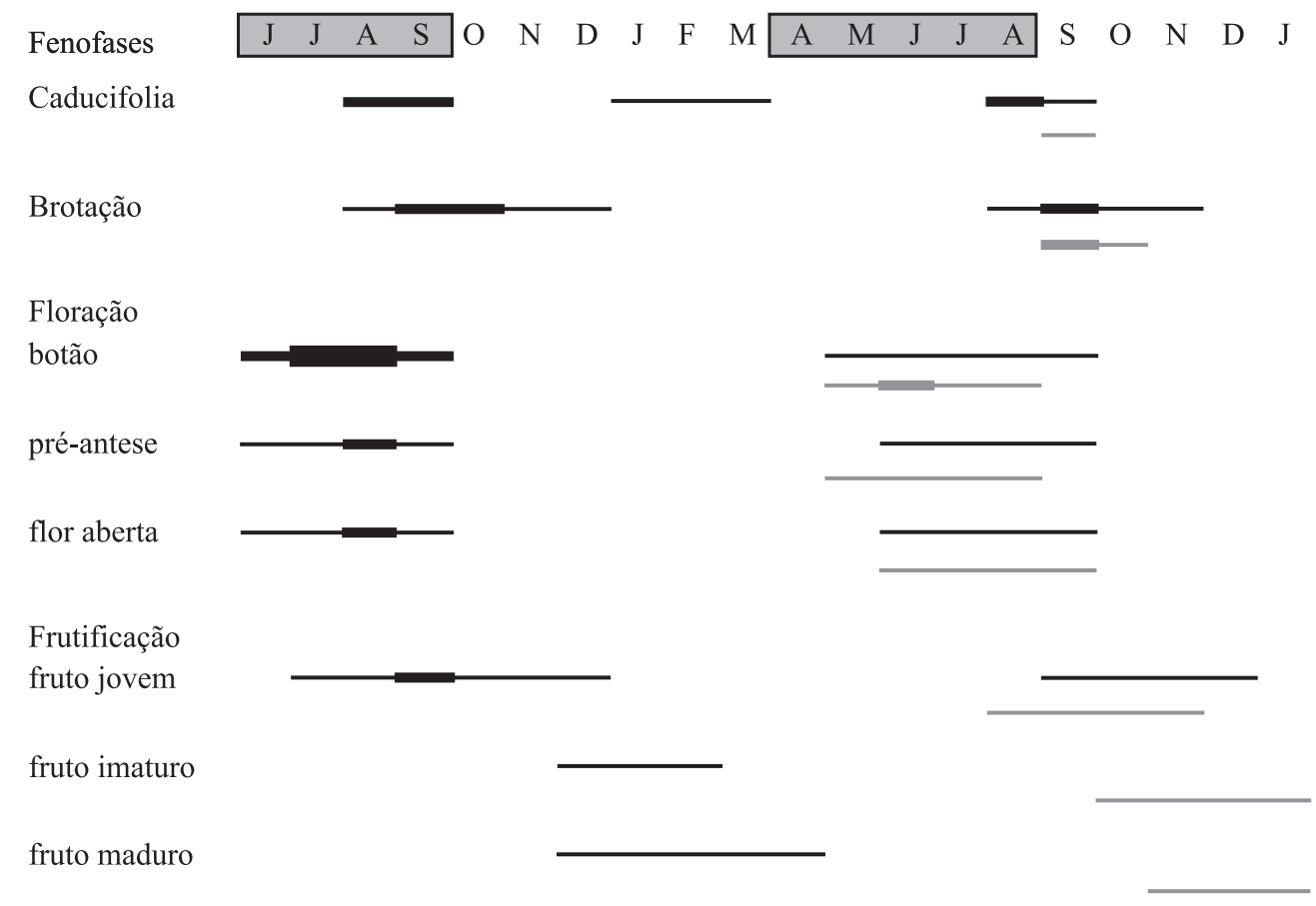

Figura 1. Fenograma de Pouteria torta referente aos meses de julho (J) de 2006 à maio $(\mathrm{M})$ de 2007 e de Pouteria ramiflora de julho (J) de 2005 à maio (M) de 2007, no cerrado sentido restrito da Reserva Ecológica do Clube Caça e Pesca Itororó, Uberlândia-MG (barra cinza $=$ P. torta ; barra preta $=$ P. ramiflora) . A espessura das barras representa a intensidade das fenofases $(\mathrm{em}$ branco $=0 \%$; barra fina $=1 \mathrm{a} 25 \%$; barra média $=26$ a $50 \%$; barra grossa $=51$ a $75 \%)$. Os meses em destaque compreendem os meses da estação seca.

Figure 1. Phenological phases of Pouteria ramiflora (from July 2005 to May 2007) and P. torta (from July 2006 to May 2007), in the cerrado strict sense of the Natural Reserve of Clube Caça e Pesca Itororó, Uberlândia-MG (black bar = P. ramiflora; gray bar $=P$. torta) . The bar thickness represents the intensity of the phenophases (white $=0 \%$; thin bar $=1$ to $25 \%$; mean bar $=26$ to $50 \%$; thick bar $=51$ to $75 \%$ ). The seconded months indicate the months of dry the season. 
al. 2005, Lenza \& Klink 2006), e de outros ambientes sazonais com estação seca bem definida (Monasterio \& Sarmiento 1976, Sarmiento \& Monasterio 1983). Segundo Janzen (1967), a perda das folhas durante a floração proporciona uma maior exposição das estruturas florais, favorecendo a atração de polinizadores.

Em 2005, a brotação em Pouteria ramiflora iniciouse no final de agosto, estendendo-se até dezembro, e em 2006, ocorreu de agosto a novembro, períodos correspondentes à transição da estação seca para a estação chuvosa (figura 1). A brotação em $P$. torta ocorreu de setembro ao início de outubro, também na transição da estação seca para a estação chuvosa (figura 1). Em ambas as espécies, a emissão dos brotos foliares foi iniciada logo após os indivíduos começarem a perder as folhas secas, o que permite caracterizá-las como brevidecíduas (Sarmiento \& Monasterio 1983). A emissão de folhas no final da estação seca pode ser tanto uma consequência da redução da perda de água induzida pela queda das folhas (Reich \& Borchert 1984) como de um estímulo causado pela chegada das primeiras chuvas (Miranda 1995).

Nos dois anos de estudo, a floração em $P$. ramiflora ocorreu de maio a setembro, com pico de flores abertas em agosto, em plena estação seca. No primeiro ano, a floração foi bem mais intensa (figura 1). A floração em $P$. torta ocorreu no mesmo período da floração de $P$. ramiflora (figura 1), mas com a maior intensidade de produção de flores abertas registrada no final de junho (20\%). No mês seguinte, houve uma drástica redução na quantidade de flores. Após alguns dias sem flores abertas, ocorreu um novo pico (final de agosto), porém menos intenso (15\%). De acordo com o padrão de classificação de Newstrom et al. (1994), as espécies apresentaram floração do tipo sazonal e anual, registrado também para outras espécies arbóreas de cerrado (Araújo et al. 1987, Freitas \& Oliveira 2002) e de outros ambientes savânicos (Monasterio \& Sarmiento 1976). Floração anual e com um único episódio ao ano foi observada também para Manilkara amazonica (Huber) A.Chev. (Alencar 1990), Chrysophyllum gonocarpum (Mart. \& Eichler) Engl. (Bianchi et al. 2006), Pouteria venosa, Manilkara subsericea e Sideroxylon obtusifolium (Gomes et al. 2008). A floração sazonal, na estação seca, também foi registrada para Pouteria venosa, Manilkara subsericea e Sideroxylon obtusifolium, Pouteria guianensis Aubl., Radlkoferella macrocarpa (Hubr.) Aubr., Chrysophyllum oppositum (Ducke) Ducke, Ragala ucuquirana-branca (Aubr \& Pellegr.) W.Rodr. e Ragala ulei (Krause) Aubr. (Alencar 1994).

A floração em $P$. ramiflora é semelhante ao tipo cornucópia (Gentry 1974), com um grande número de flores produzidas por planta por vários meses. Apesar de P. torta também florescer em grande quantidade e por vários meses, a sua floração ocorreu com dois picos de produção de flores com um pequeno intervalo entre eles. Este padrão foi semelhante à floração em pulsos (Proença \& Gibbs 1994), que também foi registrada para Myrcia tomentosa (Aubl.) DC. (Myrtaceae) em cerrados da região (Torezan-Silingardi \& Oliveira 2004). A floração durante a época seca permite a liberação das sementes dos frutos no início da estação úmida, que é o período mais propício para a germinação e estabelecimento das plântulas em espécies de cerrado (Oliveira 2008). Além disso, o clima é favorável, sem chuvas pesadas que afetem a disponibilidade de flores e os serviços de polinização (Proença \& Gibbs 1994).

Em 2005, a frutificação em $P$. ramiflora ocorreu de julho a abril, com a maturação dos frutos durante a estação chuvosa, e em 2006, ocorreu de setembro a dezembro, não havendo maturação, pois todos os frutos foram abortados no início do desenvolvimento (figura 1). Nestes anos, a intensidade máxima de frutificação ocorreu em setembro, período em que os frutos ainda estavam jovens. A frutificação em $P$. torta ocorreu de julho a janeiro, com a maturação dos frutos na época chuvosa. Do mesmo modo que $P$. ramiflora, a intensidade máxima de frutificação ocorreu em setembro, mês no qual os frutos estavam no início do desenvolvimento (figura 1). Na família Sapotaceae, um alto índice de aborto de frutos também foi registrado para $P$. venosa, Manilkara subsericea e Sideroxylon obtusifolium (Gomes et al. 2008). Quanto à maturação dos frutos no período chuvoso, como registrado em $P$. torta e $P$. ramiflora, trata-se de uma situação comum em espécies arbóreas zoocóricas de ambientes sazonais (Batalha \& Martins 2004). Nesta época, os frutos permanecem atrativos por mais tempo, favorecendo a dispersão das sementes (Batalha \& Mantovani 2000).

Biologia floral - Pouteria ramiflora possui flores pequenas, tubulares, tetrâmeras, com corola esverdeada e apêndices alternipétalos glabros. As flores estão arranjadas em inflorescências racemosas com eixo curto, dispostas densamente nas axilas das folhas, ao longo dos ramos (figura 2). O pedicelo, o cálice, o ovário e o estilete são bastante pilosos. Todos os indivíduos investigados na área de estudo apresentaram dois tipos de flores: hermafroditas e pistiladas. Estes dois morfos florais são semelhantes quanto à cor e à forma, mas as flores pistiladas são significativamente menores (tabela 1) e possuem pequenos filetes sem anteras (estaminódios) (figuras 3, 4). A flor hermafrodita apresenta androceu 
com quatro estames e cada filete inserido em uma pétala. Os estames são inclusos, com as anteras próximas à altura do estigma e em posição alternada com os apêndices das pétalas (figura 3). Em conjunto, as anteras e os apêndices restringem a abertura do tubo da corola, protegendo o néctar acumulado no fundo do tubo. As anteras são rimosas, em forma de lança, e os grãos de pólen ficam espalhados em torno da antera após a sua liberação. As flores pistiladas e hermafroditas possuem estigma inteiro, puntiforme e úmido; ovário súpero com dois lóculos e um óvulo em cada lóculo. Contudo, algumas flores hermafroditas analisadas possuíam um ou ambos os lóculos sem óvulo.

Pouteria torta também possui flores pequenas, mas maiores que ambos os tipos florais de $P$. ramiflora (tabela 1). As flores são esverdeadas, com pedicelo curto (quase sésseis) e posicionadas de forma isolada ou agrupada, caracterizando a caulifloria (figura 5). A corola é tubular, com quatro pétalas (figura 6) e quatro apêndices alternipétalos com formato de lança dispostos mais ou menos na altura das anteras. $\mathrm{O}$ androceu é composto por quatro estames inclusos, cada um inserido próximo à base de uma pétala, tendo anteras com deiscência longitudinal extrorsa. O gineceu apresenta ovário súpero, usualmente com quatro óvulos, e o estigma é tetralobado e exposto antes da abertura da flor (figura 7). De modo semelhante à Pouteria ramiflora, o pedicelo, o cálice e o ovário são pilosos.

Flores pistiladas ainda apresentando filetes ou estaminódios, como observado em P.ramiflora e também em P. ucuqui Pires \& R.E. Schult. (Pennington 1990), representam a forma mais simples de dimorfismo existente
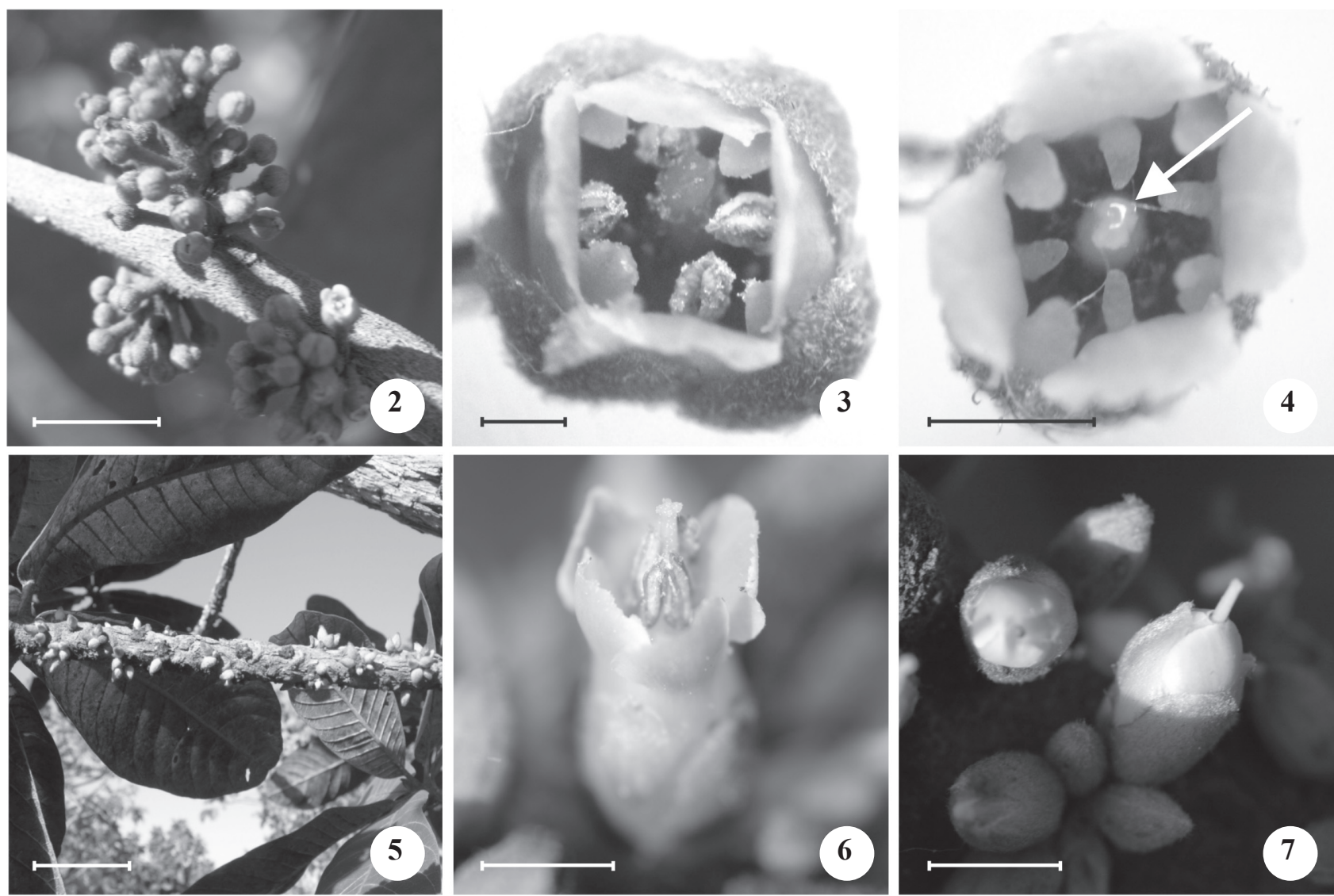

Figuras 2-7. Detalhes morfológicos de Pouteria ramiflora: inflorescências racemosas (2); flor hermafrodita (observar os grãos de pólen no estigma) (Foto: Custódio, L.N) (3); flor pistilada (seta indicando o estigma úmido, com substância colante) (Foto: Custódio, L.N) (4), e de Pouteria torta: caulifloria (5); flor aberta (6); botão com estigma receptivo (7). Barra: $=1 \mathrm{~cm}(2)$; $1 \mathrm{~mm}(3-4) ; 3 \mathrm{~cm}(5) ; 3 \mathrm{~mm}(6) ; 5 \mathrm{~mm}(7)$.

Figures 2-7. Morphological details of Pouteria ramiflora: racemous inflorescences (2); hermaphrodite flower (observe the pollen grains on the stigma) (Photo: Custódio, L.N) (3); female flower (arrow showing the wet stigma, with gluey substance) (Photo: Custódio, L.N) (4), and of Pouteria torta: flowers arranged on the stem (5); opened flower (6); bud with receptive stigma (7). Bar: = $1 \mathrm{~cm} \mathrm{(2);} 1 \mathrm{~mm}(3-4) ; 3 \mathrm{~cm}(5) ; 3 \mathrm{~mm}$ (6); $5 \mathrm{~mm}$ (7). 
Tabela 1. Medidas (mm) das flores de Pouteria ramiflora e P. torta. Letras diferentes em cada linha indicam diferenças significativas ao nível de $1 \%$ comparadas usando teste $t$. Com exceção do diâmetro da corola, as demais medidas são referentes ao comprimento.

Table 1. Measures (mm) of Pouteria ramiflora and P. torta flowers. Different letters in each row indicate significant differences at $1 \%$ level compared using Student's $t$-test. All measures, but the corolla diameter, are referent to the length.

\begin{tabular}{lccr}
\hline $\begin{array}{l}\text { Flor e peças florais } \\
(\mathrm{mm})\end{array}$ & $\begin{array}{c}\text { Pouteria ramiflora } \\
\text { flor hermafrodita } \\
\bar{x} \pm \text { D.P. }(n=45)\end{array}$ & $\begin{array}{c}\text { Pouteria ramiflora } \\
\text { flor pistilada } \\
\bar{x} \pm \text { D.P. }(n=25)\end{array}$ & $\begin{array}{r}\text { Pouteria torta } \\
\bar{x} \pm \text { D.P. }(n=35)\end{array}$ \\
\hline Flor & $9 \pm 2,9 \mathrm{a}$ & $5,5 \pm 0,9 \mathrm{~b}$ & $12 \pm 0,9 \mathrm{c}$ \\
Tubo da corola & $4 \pm 0,4 \mathrm{a}$ & $3,6 \pm 0,3 \mathrm{~b}$ & $9 \pm 0,1 \mathrm{c}$ \\
Diâmetro da corola & $3 \pm 0,5 \mathrm{a}$ & $2,3 \pm 0,3 \mathrm{~b}$ & $4,4 \pm 0,7 \mathrm{c}$ \\
Cálice & $3 \pm 0,3 \mathrm{a}$ & $2,1 \pm 0,1 \mathrm{~b}$ & $7 \pm 0,9 \mathrm{c}$ \\
Apêndice da pétala & $1,2 \pm 0,2 \mathrm{a}$ & $0,9 \pm 0,2 \mathrm{~b}$ & $2 \pm 0,3 \mathrm{c}$ \\
Filete & $1,2 \pm 0,3 \mathrm{a}$ & $0,8 \pm 0,2 \mathrm{~b}$ & $4 \pm 0,6 \mathrm{c}$ \\
Antera & $0,9 \pm 0,1 \mathrm{a}$ & - & $2,5 \pm 0,3 \mathrm{~b}$ \\
Pistilo & $3 \pm 0,3 \mathrm{a}$ & $2 \pm 0,3 \mathrm{~b}$ & $10 \pm 1,0 \mathrm{c}$ \\
\hline
\end{tabular}

neste gênero. Dimorfismos mais marcados ocorrem em P. nudipetala T.D. Penn., que não apresenta estames, e em P. durlandii (Standl.) Baehni, que teve perda total das anteras, redução do tamanho dos estaminódios e grande redução do tamanho das flores pistiladas (Pennington 1990). A redução no tamanho das flores pistiladas tem sido observada em muitas espécies ginodióicas e ginomonóicas, podendo afetar a visita dos polinizadores, que, geralmente, preferem as flores hermafroditas por estas disponibilizarem maior quantidade de recursos para o forrageamento (Delph 1996).

A abertura das flores em $P$. ramiflora ocorreu ao longo do dia, de modo que, em qualquer horário, podiam ser encontrados botões e flores em diferentes fases de desenvolvimento uma mesma inflorescência. Em $P$. torta, a abertura ocorreu ao longo da manhã e as flores permaneceram abertas por cerca de dois dias, enquanto em $P$. ramiflora, duraram cerca de um dia. Em P. ramiflora, o estigma tornava-se receptivo quando as flores se abriam. Nos dois morfos florais, o estigma apresentava uma secreção úmida de consistência viscosa, aspecto colante e coloração clara nesta fase (figura 4). O pólen começava a ser liberado na fase de botão fechado, estando viável nas flores recém abertas, com uma viabilidade média de 93,5 $\pm 4,0 \%(n=15)$. Em P. torta, a distensão do estilete ocorreu quando as pétalas estavam expostas, mas ainda fechadas e a receptividade estigmática iniciou-se nesta fase. No entanto, o estigma permaneceu receptivo na flor durante o período em que o pólen estava sendo liberado, o que caracteriza a dicogamia incompleta. A dicogamia consiste na separação temporal da expressão sexual das flores, podendo ser completa ou incompleta dependendo do grau de separação dessas duas funções, isto é, em virtude da ocorrência ou não de alguma sobreposição entre a oferta de pólen e o período em que o estigma encontra-se receptivo. Tal dicogamia e protoginia já haviam sido descritas para P. torta (Gottsberger \& Silberbauer-Gottsberger 2006) e para outras Sapotaceae como Manilkara subsericea e Sideroxylon obtusifolium (Gomes et al. 2010). A viabilidade polínica média foi de $99 \pm 1,3 \%$ ( $n=15$ flores $)$.

O volume médio de néctar dos botões em préantese (hermafrodita) de Pouteria ramiflora foi de $0,16 \pm 0,03 \mu 1(n=10)$ e sua concentração média foi de $30,0 \pm 3,16 \%$ ou $0,3377 \pm 0,04 \mathrm{mg} / \mu \mathrm{l}(n=10)$. Não foi possível avaliar o volume e a concentração de néctar das flores pistiladas devido à dificuldade de se retirar a pequena quantidade de néctar presente nestas flores. Os botões em pré-antese de $P$. torta apresentaram néctar com um volume médio de $7 \pm 3,0 \mu 1(n=10)$ e concentração média de $20 \pm 2,5 \%$ ou $0,2132 \pm 0,03 \mathrm{mg} / \mu \mathrm{l}(n=10)$, podendo-se observar que o néctar teve volume bem maior, mas concentração menor do que o néctar das flores de $P$. ramiflora. Nesta espécie, o pequeno volume de néctar pode ser importante para que os polinizadores visitem várias flores e se movimentem mais entre as plantas. De acordo com Navarro (1999), uma pequena quantidade de néctar por flor favorece o movimento dos polinizadores para outras flores e para outras plantas. A concentração de néctar das flores de $P$. ramiflora e de $P$. torta é consideravelmente alta e semelhante à concentração em outras espécies de cerrado visitadas por abelhas (Barbosa \& Sazima 2008) e moscas (Machado 
\& Oliveira 2000), sendo uma fonte de energia bastante atrativa para os visitantes florais.

As flores de P. ramiflora e de P. torta apresentam odor similar (doce, forte e agradável), possível de ser detectado a cerca de $1 \mathrm{~m}$ de distância das árvores floridas. A presença de odor nas flores é importante, pois este recurso é um atrativo floral à longa distância, especialmente para insetos como mariposas e dípteros (Knudsen \& Tollsten 1991, Proctor et al. 1996, Raguso 2008).

Sistema reprodutivo - Em $P$. ramiflora, as flores hermafroditas submetidas aos tratamentos de autopolinização manual $(n=52)$ e apomixia autônoma $(n=27)$ não resultaram em frutos. Apesar de ter ocorrido formação de frutos por autopolinização espontânea $(2,55 \%)$, todos foram abortados até o terceiro mês de desenvolvimento (tabela 2). A dissecção de uma grande quantidade dos frutos abortados permitiu verificar que todos possuíam sementes em início de formação, sem evidência de predação por larvas de insetos. Em P. torta, não houve formação de frutos nos testes de autopolinização manual $(n=129)$, autopolinização espontânea $(n=522)$ e apomixia $(n=94)$ (tabela 2$)$.
Estes resultados indicam que Pouteria ramiflora e $P$. torta são espécies autoestéreis e que a reprodução sexuada é a única forma pela qual os frutos são produzidos. Nas flores hermafroditas de $P$. ramiflora, a deposição de pólen sobre a própria superfície estigmática pode ocorrer devido às anteras estarem dispostas na altura do estigma. Contudo, o aborto dos frutos formados a partir deste processo otimiza a alocação de recursos para os frutos formados por polinizações cruzadas (Gibbs 1990), e por ter ocorrido em frutos iniciais com tamanhos bem variados, deve ser resultado de depressão endogâmica (Sage et al. 1994).

Nos dois anos de estudo, a polinização cruzada entre flores hermafroditas de $P$. ramiflora resultou na formação de um único fruto $(n=109)$ que, no entanto, não chegou à maturação (tabela 2). Entre as flores pistiladas submetidas ao teste de polinização cruzada $(n=26)$, seis formaram frutos, mas apenas três se desenvolveram até a maturação, com sucesso de frutificação de 11,5\% (tabela 2). Tais resultados indicam que somente as flores pistiladas produzem frutos viáveis e que as flores hermafroditas atuam como doadoras de pólen. Em 2005, o sucesso de frutificação das polinizações naturais foi de $6,63 \%(n=1480)$ e em

Tabela 2. Resultados dos experimentos de polinização em Pouteria ramiflora e em P. torta, em 2005 e em 2006 , no cerrado sentido restrito da Reserva Ecológica do Clube Caça e Pesca Itororó, Uberlândia, MG. ( $Q=$ flores pistiladas; $-=$ sem informação).

Table 2. Results of pollination experiments in Pouteria ramiflora and in P. torta, in 2005 and 2006, in the cerrado (sensu stricto) of the Natural Reserve of the Clube Caça e Pesca Itororó, Uberlândia, MG. ( $Q=$ pistilate flowers; $-=$ no information).

\begin{tabular}{|c|c|c|c|c|c|c|c|c|}
\hline \multirow{2}{*}{ Tratamentos } & \multicolumn{2}{|c|}{ № flores } & \multicolumn{2}{|c|}{ № frutos iniciados } & \multicolumn{2}{|c|}{ № frutos maduros } & \multicolumn{2}{|c|}{$\begin{array}{c}\text { Sucesso de } \\
\text { frutificação }(\%)\end{array}$} \\
\hline & 2005 & 2006 & 2005 & 2006 & 2005 & 2006 & 2005 & 2006 \\
\hline \multicolumn{9}{|c|}{ Autopolinização manual } \\
\hline P. ramiflora & 24 & 80 & 0 & 0 & 0 & 0 & 0 & 0 \\
\hline P. torta & 47 & 82 & 0 & 0 & 0 & 0 & 0 & 0 \\
\hline \multicolumn{9}{|c|}{ Autopolinização espontânea } \\
\hline P. ramiflora & 1905 & 3705 & 41 & 102 & 0 & 0 & 0 & 0 \\
\hline P. torta & 72 & 450 & 0 & 0 & 0 & 0 & 0 & 0 \\
\hline \multicolumn{9}{|l|}{ Apomixia } \\
\hline P. ramiflora & 7 & 20 & 0 & 0 & 0 & 0 & 0 & 0 \\
\hline P. torta & 16 & 78 & 0 & 0 & 0 & 0 & 0 & 0 \\
\hline \multicolumn{9}{|c|}{ Polinização cruzada } \\
\hline P. ramiflora & 35 & 74 & 1 & 1 & 0 & 0 & 0 & 0 \\
\hline P. torta & - & 35 & - & 6 & - & 6 & - & 17 \\
\hline \multicolumn{9}{|c|}{ Polinização cruzada $(+)$} \\
\hline P. ramiflora & - & 26 & - & 6 & - & 3 & - & 11,5 \\
\hline \multicolumn{9}{|c|}{ Polinização aberta } \\
\hline P. ramiflora & 1480 & 3500 & - & - & 98 & 0 & 6,63 & 0 \\
\hline P. torta & - & 151 & - & - & - & 5 & - & 7,55 \\
\hline
\end{tabular}


2006, foi nulo $(n=3500)$, pois todos os frutos foram abortados no início do desenvolvimento (tabela 2). Em $P$. torta, as polinizações cruzadas e as polinizações naturais resultaram em $17(n=35)$ e 7,55\% $(n=151)$ de sucesso de frutificação, respectivamente (tabela 2). Estes resultados, assim como os obtidos em $P$. ramiflora, mostraram que a produção de frutos por polinização natural é baixa e inferior à obtida por polinização cruzada manual. $\mathrm{O}$ grande número de flores exibido diariamente em cada planta pode contribuir para a geitonogamia ou autopolinização mediada por polinizadores, mesmo que as espécies possuam estratégias sexuais para evitá-la. Grandes quantidades de flores exibidas por dia em cada planta podem limitar o movimento dos polinizadores e reduzir o fluxo de pólen entre as plantas, favorecendo a autopolinização (Stephenson 1981). A autogamia e a geitonogamia geram custos como a redução da quantidade de pólen doada para plantas coespecíficas, redução de óvulos disponíveis para a fertilização cruzada e aumento da depressão endogâmica (Williams 2007). Além disso, a transferência interespecífica de pólen pode estar interferindo no sucesso reprodutivo das espécies estudadas. Espécies que florescem no mesmo período podem sofrer limitação no sucesso reprodutivo em função do compartilhamento de visitantes, sendo que este efeito pode ocorrer mesmo que as espécies possuam polinizadores adicionais, não compartilhados entre si (Waser 1978).

Sistema sexual - As observações feitas no campo e as análises de laboratório indicaram que Pouteria ramiflora é ginomonóica, possuindo um sistema sexual presente em apenas cerca de 3\% das angiospermas (Richards 1997). As flores hermafroditas são bastante semelhantes às flores pistiladas (figuras 3,4), entretanto, embora formem óvulos aparentemente bem desenvolvidos, não produziram frutos e parecem ser funcionalmente masculinas. Assim sendo, $P$. ramiflora pode ser considerada uma espécie funcionalmente monóica. De qualquer modo, os dados sobre o sistema sexual de $P$. ramiflora obtidos na população estudada não coincidem com os da literatura, na qual a espécie foi classificada como dióica (Pennington 1990), hermafrodita (Almeida et al. 1998) ou funcionalmente dióica (Oliveira 1996). Porém, estes trabalhos descreveram o sistema sexual com base em características morfológicas observadas no campo, não envolvendo testes de laboratório e de polinização.

Nas amostras de flores de 26 indivíduos de $P$. ramiflora, as flores pistiladas representaram em média $15,4 \pm 18,3 \%$ do total de flores em $2005 \quad(n=22$ indivíduos) e 21,2 $\pm 24,8 \%$ das flores em 2006 ( $n=7$ indivíduos), mas a proporção de cada morfo floral variou amplamente entre os indivíduos. Há plantas que possuem um pequeno número de flores pistiladas (situação mais comum) e outras em que a quantidade parece ser similar à de flores hermafroditas. Mesmo que em algumas amostras tenham sido encontradas apenas flores de um único morfo, observações complementares mostraram que em nenhum caso existiam indivíduos com apenas um tipo de flor. Esta diferença nas proporções dos tipos florais ocorre em espécies monóicas, ginomonóicas e andromonóicas, podendo representar uma dificuldade para o diagnóstico do sistema sexual das espécies (Gross 2005). Geralmente, as flores pistiladas ocorrem agrupadas em determinados ramos, podendo dificultar a sua visualização nas plantas. Também não é comum ocorrerem em uma mesma inflorescência que as flores hermafroditas, podendo ser uma estratégia para evitar a geitonogamia.

A separação espacial das funções sexuais das flores é muito comum em espécies com flores pequenas, agregadas em inflorescências e de polinização imprecisa, isto é, com o pólen de flores de uma mesma planta impedindo a deposição de pólen das plantas coespecíficas (Bawa $\&$ Beach 1981). Considerando que as flores pistiladas estão presentes em menor quantidade e que somente elas produzem frutos, a sua semelhança com as flores hermafroditas quanto à cor, forma, presença de néctar e odor, é importante para que também sejam visitadas. A produção de flores femininas pode reduzir as visitas de polinizadores, pois estas flores podem ser evitadas até mesmo pelos polinizadores que não consomem o pólen, mas que utilizam as anteras como um guia para a orientação visual (Charlesworth 1993).

Pouteria torta possui somente flores hermafroditas, cujo estilete é exposto ainda na fase de botão (figura 7). Nas flores em antese, as anteras ficavam encostadas no estilete e abaixo do estigma $(1,5 \mathrm{~mm} ; n=10)$ (figura 6), podendo ser essa diferença entre a altura das estruturas reprodutivas interpretada como hercogamia de aproximação. As polinizações cruzadas experimentais resultaram na formação de frutos em quatro das cinco flores polinizadas com o estigma exposto antes da abertura e em uma das 12 flores abertas. O fruto formado a partir da polinização da flor aberta indica que o estigma parece continuar receptivo depois de iniciada a liberação do pólen e corrobora a idéia de dicogamia incompleta. Pouteria torta pode ser caracterizada como hermafrodita, com dicogamia incompleta (protoginia) e separação espacial (hercogamia) nas funções sexuais das flores. Na família Sapotaceae, Manilkara subsericea 
e Sideroxylon obtusifolium também são hercogâmicas e protogínicas (Gomes et al. 2010). Tanto a antecipação da receptividade estigmática em relação à liberação polínica, como a diferença de altura entre o estigma e o androceu são estratégias que evitam a deposição do pólen da flor sobre o próprio estigma, contribuindo para impedir a autopolinização. Estas estratégias são importantes mesmo em espécies autoincompatíveis, pois a deposição do pólen sobre o estigma da mesma flor reduz a quantidade a ser doada, limita o espaço na superfície estigmática para a adesão de pólen de flores de plantas coespecíficas, e impossibilita a germinação e o crescimento destes grãos de pólen (Lloyd \& Webb 1986).

Sistema de polinização - Apesar das diferenças no tamanho das flores, o espectro de visitantes das espécies estudadas não foi marcadamente diferente. As flores de Pouteria ramiflora foram visitadas por lepidópteros (48\% dos 156 visitantes observados), dípteros (28\%), himenópteros (20\%, sendo abelhas $12 \%$ e vespas $8 \%)$, heterópteros e trips (tabela 3). Pequenos lépidopteros sempre tocavam as estruturas reprodutivas ao pousarem nas flores e nas análises em laboratório foram encontradas muitos grãos de pólen na cabeça desses insetos. Uma mosca pertencente à família Chloropidae foi a única que sempre adentrava o tubo da corola para a coleta do néctar em Pouteria ramiflora.

Apesar das limitações no tempo de observação e dificuldades para quantificar as coletas, verificou-se que as flores de $P$. torta foram visitadas por lepidópteros (borboletas), dípteros (moscas) e himenópteros (abelhas pequenas como Trigona spinipes (Fabricius) e Apis mellifera (Linnaeus), e vespas). Em contraste com $P$. ramiflora, onde raramente foram observadas tocando as estruturas reprodutivas, as abelhas pequenas foram muito comuns em $P$. torta e são polinizadores potenciais. Tanto em $P$. ramiflora como em $P$. torta, os visitantes florais utilizaram principalmente o néctar como recurso. Gottsberger e Silberbauer-Gottsberger (2006) observaram um espectro semelhante de visitantes para ambas as espécies, mas indicam que a atividade

Tabela 3. Visitantes florais de Pouteria ramiflora no período de 2005 e 2006, no cerrado sentido restrito da Reserva Ecológica do Clube Caça e Pesca Itororó, Uberlândia-MG (si = sem identificação).

Table 3. Pouteria ramiflora floral visitors in 2005 and 2006, in an area of cerrado stricto sensu of the Clube Caça e Pesca Itororó Ecological Reserve, Uberlândia-MG (si = unidentified).

\begin{tabular}{|c|c|c|c|}
\hline Ordem/Família & Espécie & Pólen no corpo & Recurso explorado \\
\hline \multicolumn{4}{|l|}{ LEPIDOPTERA } \\
\hline Lycaenidae & Emesis sp.1 & $\operatorname{sim}$ & néctar \\
\hline Lycaenidae & Emesis sp. 2 & $\operatorname{sim}$ & néctar \\
\hline Lycaenidae & Panthiades sp. & $\operatorname{sim}$ & néctar \\
\hline Lycaenidae & Sofrasta sp. & $\operatorname{sim}$ & néctar \\
\hline Lycaenidae & Thecla sp. & $\operatorname{sim}$ & néctar \\
\hline Nymphalidae & Temenis sp. & $\operatorname{sim}$ & néctar \\
\hline Pyralidae & si & $\operatorname{sim}$ & néctar \\
\hline \multicolumn{4}{|l|}{ DIPTERA } \\
\hline Calliphoridae & Phaenicia eximia (Wiedemann 1819) & $\operatorname{sim}$ & néctar \\
\hline Chloropidae & si & $\operatorname{sim}$ & néctar \\
\hline Limoniidae & Limonia sp. & não & néctar \\
\hline Limoniidae & Toxorhina sp. & não & néctar \\
\hline Syrphidae & si & não & néctar \\
\hline Sarcophagidae & Blaesoxipha (Acanthodotheca) sp.* & $\operatorname{sim}$ & néctar \\
\hline Tachinidae & si & $\operatorname{sim}$ & néctar \\
\hline \multicolumn{4}{|c|}{ HYMENOPTERA } \\
\hline Apoidea & Halictinae sp. 1 & não & néctar \\
\hline Apoidea & Halictinae sp. 2 & $\operatorname{sim}$ & pólen \\
\hline Apidae & Trigona spinipes (Fabricius 1793) & não & néctar \\
\hline Vespidae & Polybia paulista (Ihering 1890) & não & - \\
\hline Vespidae & Polybia sp. & não & - \\
\hline Vespidae & Mischocyttarus cerberus styx (Richards 1940) & não & - \\
\hline
\end{tabular}


nas flores é maior durante a noite, sendo lepidópteros e coleópteros os principais visitantes.

As flores pequenas e de cor clara exibidas por $P$. torta e $P$. ramiflora são autoestéreis e requerem polinização biótica. A ginomonoicia em $P$. ramiflora e a protoginia e hercogamia em $P$. torta podem ser vistas como formas de otimizar a polinização pouco especializada por pequenos insetos. Apesar de diferenças de tamanho e dinâmica de floração, as espécies possuem florescimento simultâneo e flores semelhantes quanto a cor, forma geral e odor, compartilhando um espectro semelhante de visitantes florais.

Agradecimentos - Ao CNPq pelo apoio financeiro recebido durante a Iniciação Científica (PIBIC CNPq/UFU B021/2005); aos pesquisadores Dra. Cecília Lomônaco de Paula (UFU), Dr. Kleber Del Claro (UFU), Dra. Fernanda Helena Nogueira Ferreira (UFU), Dr. Júlio Mendes (UFU), Dr. Guilherme Cunha Ribeiro (USP), Dr. Jonas Byk e à Bióloga Estefane Nascimento Leoncini Siqueira pelas identificações dos insetos coletados; ao MSc João Fernandes da Silva do Instituto de Geografia (UFU) pelo fornecimento dos dados climatológicos. Aos dois revisores do trabalho original que deram contribuição fundamental para a melhoria do trabalho.

\section{Referências bibliográficas}

ALENCAR, J.C. 1990. Interpretação fenológica de espécies lenhosas de Campina na Reserva Biológica de Campina do INPA ao Norte de Manaus. Acta Amazonica 20:145183.

ALENCAR, J.C. 1994. Fenologia de cinco espécies arbóreas tropicais de Sapotaceae correlacionadas a variáveis climáticas na Reserva Ducke, Manaus, AM. Acta Amazonica 24:161-182.

ALMEIDA, S.P., PROENÇA, C.E.B., SANO, S.M. \& RIBEIRO, J.F. 1998. Cerrado: espécies vegetais úteis. EMBRAPA-CPAC, Planaltina.

ARAÚJO, G.M., FRANCISCON, C.H. \& NUNES, J.G. 1987. Fenologia de nove espécies arbóreas de um cerrado no município de Uberlândia, MG. Revista Centro de Ciências Biomédicas da Universidade Federal de Uberlândia 3:3-17.

BARBOSA, A.A.A. \& SAZIMA, M. 2008. Biologia reprodutiva de plantas herbáceo-arbustivas de uma área de Campo Sujo de Cerrado. In Cerrado: Ecologia e Flora (S.M. Sano, S.P. Almeida \& J.F. Ribeiro, eds.). EMBRAPA-CPAC, Brasília, vol.1, p.291-307.

BATALHA, M.A. \& MANTOVANI, W. 2000. Reproductive phenology patterns of cerrado plant species at the Pé-deGigante Reserve (Santa Rita do Passa Quatro, SP, Brazil): a comparison between the herbaceous and woody flora. Revista Brasileira de Biologia 60:129-145.
BATALHA, M.A. \& MARTINS, F.R. 2004. Reproductive phenology of the cerrado plant community in Emas National Park (central Brazil). American Journal of Botany 52:149-161.

BAWA, K.S. 1980. Evolution of dioecy in flowering plants. Annual Review of Ecology and Systematics 11:15-39.

BAWA, K.S. \& BEACH, J.H. 1981. Evolution of sexual systems in flowering plants. Annals of the Missouri Botanical Garden 68:254-274.

BENCKE, C.S.C.\& MORELLATO, L.P.C. 2002. Comparação de dois métodos de avaliação da fenologia de plantas, sua interpretação e representação. Revista Brasileira de Botânica 25:269-275.

BERTIN, R.I. 1993. Incidence of monoecy and dichogamy in relation to self-fertilization in angiosperms. American Journal of Botany 80:557-560.

BIANCHI, E., PIMENTA, J.A. \& SANTOS, F.A.M. 2006. Fenologia de Chrysophyllum gonocarpum (Mart. \& Eichler) Engl. (Sapotaceae) em floresta semidecídua do Sul do Brasil. Revista Brasileira de Botânica 29: 595-602.

CHARNOV, E.L. 1979. Simultaneous hermaphroditism and sexual selection. Proceedings of the National Academy of Sciences 76:2080-2484.

CHARNOV, E.L., BULL, J.J. \&. MAYNARD SMITH, J. 1976. Why be an hermafrodite? Nature 263:125-126.

CHARLESWORTH, D. 1993. Why are unisexual flowers associated with wind pollination and unspecialized pollinators? The American Naturalist 141:481-490.

CORRALES, F.M., MANTOVANI, W. \& CATHARINO, E.L.M. 1986. Estudos preliminares da biologia floral de Chrysophyllum auratum Miq. (Sapotaceae) em Piracicaba, Estado de São Paulo. Anais da Escola Superior de Agricultura Luiz de Queiroz 43: 147-157.

DAFNI, A., KEVAN, P.G. \& HUSBAND, B.C. 2005. Practical pollination biology. Enviroquest Ltd., Cambridge, Ontario.

DARLINGTON, C.D. 1958. The evolution of genetic systems. $2^{\text {ed }}$, Oliver and Boyd, London.

DELPH, L.F. 1996. Flower size dimorphism in plants with unisexual flowers. In Floral biology: studies on floral evolution in animal-pollinated plants (D.G. Lloyd \& S.C.H. Barret, eds.). Chapman and Hall, New York, p.217-237.

FALEIRO, W. 2007. Composição florística e estrutura da comunidade arbórea em duas áreas de cerrado sensu strict, em Uberlândia - MG. Dissertação de mestrado, Universidade Federal de Uberlândia, Uberlândia.

FRANCO, A.C., BUSTAMANTE, M., CALDAS, L.S., GOLDSTEIN, G., MEINZER, F.C., KOZOVITS, A.R., RUNDEL, P. \& CORADIN, V.T.R. 2005. Leaf functional traits of Neotropical savanna trees in relation to seasonal water deficit. Trees 19: 326-335. 
FREITAS, C.V.\& OLIVEIRA, P.E. 2002. Biologia reprodutiva de Copaifera langsdorffii Desf. (Leguminosae, Caesalpinioideae). Revista Brasileira de Botânica 25:311-321.

GENTRY, H.A. 1974. Flowering phenology and diversity in tropical Bignoniaceae. Biotropica 6:64-68.

GIBBS, P. 1990. Self-incompatibility in flowering plants: a neotropical perspective. Revista Brasileira de Botânica 13:125-136.

GOMES, R. \& PINHEIRO, M.C.B. 2007. Biologia floral de Pouteria venosa (Martius) Baehni (Sapotaceae) na restinga de Maricá-RJ. Revista Brasileira de Biociências 5:108-110.

GOMES, R., PINHEIRO, M.C.B., LIMA, H.A. \& SANTIAGO-FERNANDES, L.D.R. 2010. Biologia floral de Manilkara subsericea e de Sideroxylon obtusifolium (Sapotaceae) em restinga. Revista Brasileira de Botânica 33:271-283.

GOTTSBERGER, G. \& SILBERBAUER-GOTTSBERGER, I. 2006. Life in the Cerrado: a South American tropical seasonal ecosystem. Reta Verlag, Ulm.

GRANT, V. 1958. The regulation of recombination in plants. Cold Spring Harbor Symposium on Quantum Biology 23:337-363.

GROSS, A.L. 2005. A comparison of sexual systems in the trees from the Australian tropics with other tropical biomes - more monoecy but why? American Journal of Botany 92:907-919.

HARDER, L.D., BARRETT, S.C.H. \& COLE, W.W. 2000. The mating consequences of sexual segregation within inflorescences of flowering plants. Proceedings Royal Society of London, Series B. Biological Sciences 267:315-320.

JANZEN, D.H. 1967. Synchronization of sexual reproduction of trees within the dry season in Central America. Evolution 21:620-637.

KEARNS, C.A. \& INOUYE, D.W. 1993. Techniques for pollination biologists. University Press of Colorado, Niwot.

KNUDSEN, J.T. \& TOLLSTEN, L. 1991. Floral scent and intrafloral scent differentiation in Moneses and Pyrola (Pyrolaceae). Plant Systematics and Evolution 177: 81-91.

KURUVILLA, P.K. \& SHAH, J.J. 1988. Development and histochemistry of style and stigma, and pollen-pistil interaction in Madhuca indica (Sapotaceae). Annals of Botany 61:269-281.

LENZA, E. \& KLINK, C.A. 2006. Comportamento fenológico de espécies lenhosas em um cerrado sentido restrito de Brasília, DF. Revista Brasileira de Botânica 29:627-638.

LEWIS, D. 1942. The evolution of sex in flowering plants. Biological Reviews 17:46-67.
LLOYD, D.G. \& WEBB, C.J. 1986. The avoidance of interference between the presentation of pollen and stigmas in angiosperms. I. Dichogamy. New Zealand Journal of Botany 24:135-162.

LORENZI, H. 1992. Árvores brasileiras: manual de identificação e cultivo de plantas arbóreas do Brasil. Editora Plantarum, Nova Odessa.

MACHADO, A.O. \& OLIVEIRA, P.E. 2000. Biologia floral de Casearia grandiflora Camb. (Flacourtiaceae). Revista Brasileira de Botânica 23:283-290.

MATHER, K. 1973. Genetical structure of populations. Chapman and Hall, London.

MAYNARD SMITH, J. 1978. The evolution of sex. Cambridge University Press, Cambridge.

MENDONÇA, R.C., FELFILI, J.M. \& WALTER, B.M.T. 1998. Cerrado. In Cerrado: Ambiente e Flora (S.M. Sano \& S.P. Almeida, eds.). EMBRAPA-CPAC, Planaltina, p.289-556.

MIRANDA, I.S. 1995. Fenologia do estrato arbóreo de uma comunidade de cerrado em Alter-do-Chão, PA. Revista Brasileira de Botânica 18:235-240.

MONASTERIO, M. \& SARMIENTO, G. 1976. Phenologycal strategies of plant species in the tropical savanna and the semi-deciduous forest of Venezuelan Llanos. Journal of Biogeography 3:325-356.

NAVARRO, L. 1999. Pollination ecology and effect of néctar removal in Macleania bullata (Ericaceae). Biotropica 4:618-625.

NERD, A., IRIDJIMOVICH, V. \& MIZRAHI, Y. 1998. Phenology, breeding system and fruit development of Argan (Argan spinosa, Sapotaceae) cultivated in Israel. Economic Botanic 52:161-167.

NEWSTROM, L.E., FRANKIE, G.W. \& BAKER, H.G. 1994. A new classification for plant phenology based on flowering patterns in lowland tropical rain forest trees at La Selva, Costa Rica. Biotropica 26:141-159.

OLIVEIRA, P.E. 1996. Dioecy in the Cerrado vegetation of Central Brazil. Flora 191:235-243.

OLIVEIRA, P.E. 2008. Fenologia e biologia reprodutiva das espécies do Cerrado. In Cerrado: Ecologia e Flora (S.M. Sano, S.P. Almeida \& J.F. Ribeiro, eds.). EMBRAPACPAC, Brasília, vol.1, p.273-287.

OLIVEIRA, P.E. \& GIBBS, P.E. 2000. Reproductive biology of woody plants in a cerrado community of Central Brazil. Flora 195:311-329.

PENNINGTON, T.D. 1990. Flora Neotropica: Sapotaceae. The New York Botanical Garden, New York.

PROCTOR, M., YEO, P. \& LACK, A. 1996. The natural history of pollination. The Bath Press, London.

PROENÇA, C.E.B. \& GIBBS, P.E. 1994. Reproductive biology of eight sympatric Myrtaceae from Central Brasil. New Phytologist 126:343-354.

RAGUSO, R.A. 2008. Wake up and smell the roses: the ecology and evolution of floral scent. Annual Review of Ecology Evolution and Systematics 39:549-569. 
REICH, P.B. \& BORCHET, R. 1984. Water stress and tree phenology in a tropical dry forest in the lowlands of Costa Rica. Journal of Ecology 72:61-74.

RIBEIRO, J.E.L. DA S. 1999. Sapotaceae. In Flora da Reserva Ducke: Guia de identificação das plantas vasculares de uma floresta de terra firme na Amazônia Central. (J.E.L. da S. Ribeiro et al., orgs). INPA, Manaus, p.312-331.

RICHARDS, A.J. 1997. Plant breeding systems. Chapman and Hall, London.

ROSA, R., LIMA, S.C.C. \& ASSUNÇÃO, W.L. 1991. Abordagem preliminar das condições climáticas de Uberlândia, MG. Sociedade \& Natureza 3:91-108.

SAGE, T.L., BERTIN, R.I. \& WILLIANS, E.G. 1994. Ovarian and other late-acting self incompatibility systems. In Genetic control of self incompatibility and reproductive development in flowering plants (E.G. Williams, A.E. Clarke \& R.B. Knox, eds.). Kluwer Academic, Dordrecht, p.116-140.

SARMIENTO, G. \& MONASTERIO, M. 1983. Life forms and phenology. In Ecosystems of the word: Tropical savannas (F. Bourlière, ed.). Elsevier Science, Amsterdan, p.79-108.

SOKAL, R.R. \& ROHLF, F.J. 1981. Biometry. W.H. Freeman, New York.
STEBBINS, G.L. 1958. Longevity, habitat and the release of genetic variability in higher plants. Cold Spring Harbor Symposium on Quantum Biology 23: 365-378.

STEPHENSON, A.G. 1981. Flower and fruit abortion: proximate causes and ultimate functions. Annual Review of Ecology and Systematics 12:253-279.

TOMLINSON, P.B. 1974. Breeding mechanisms in trees. Journal of the Arnold Arboretum 55:269-290.

TOREZAN-SILINGARDI, H.M. \& OLIVEIRA, P.E. 2004. Phenology and reproductive ecology of Myrcia rostrata and M. tomentosa (Myrtaceae) in Central Brazil. Phyton 44:32-43.

WASER, N.M. 1978. Competition for hummingbird pollination and sequencial flowering in two Colorado wildflowers. Ecology 59:934-944.

WILLIAMS, C.F. 2007. Effects of floral display size and biparental inbreeding on outcrossing rates in Delphinium barbeyi (Ranunculaceae). American Journal of Botany 94:1696-1705.

WILLSON, M.F. 1979. Sexual selection in plants. American Naturalist 113:777-790.

WILLSON, M.F. 1983. Plant reproductive ecology. John Wiley \& Sons, New York. 
